\title{
University College London Library Holding ISBN: 9788366675599
}

\author{
UCL Library Services
}

Gower St, London WC1E 6BT, United Kingdom

Library Holding:

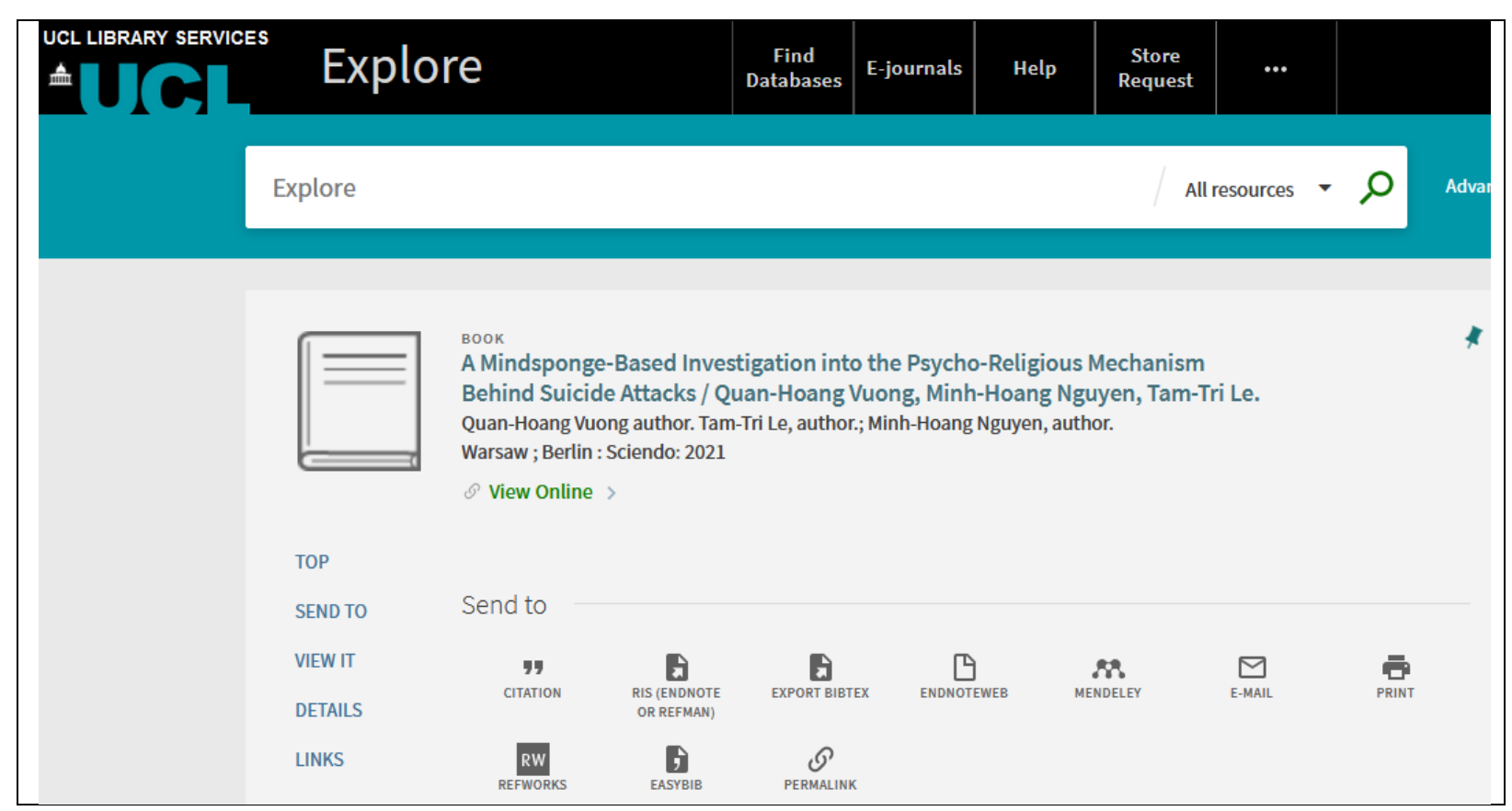


BOoK

A Mindsponge-Based Investigation into the Psycho-Religious

Mechanism Behind Suicide Attacks / Quan-Hoang Vuong, Minh-

Hoang Nguyen, Tam-Tri Le.

Quan-Hoang Vuong author. Tam-Tri Le, author.; Minh-Hoang Nguyen, author.

Warsaw ; Berlin : Sciendo: 2021

(1) View Online >

TOP

SEND TO

Send to

VIEW IT

DETAILS

LINKS

\begin{tabular}{|c|c|c|c|c|}
\hline $\begin{array}{c}97 \\
\text { CITATION }\end{array}$ & $\begin{array}{l}\text { RIS (ENDNOTE } \\
\text { OR REFMAN) }\end{array}$ & EXPORT BIBTEX $_{\text {a }}$ & $\bigsqcup_{\text {ENDNOTEWEB }}$ & Pr. \\
\hline$\square$ & 후 & RW & $B$ & 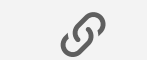 \\
\hline E-MAIL & PRINT & REFWORKS & EASYBIB & PERMALIN \\
\hline
\end{tabular}

View It

Sign in to reserve a book (all borrowing members) or request a Scan and

Send copy (UCL members only)

Full text available at: De Gruyter e-books on demand [

Authentication notes: UCL username and password required for off-site access

Public notes:

Access to this e-book is part of an E-books on demand@UCL $\square$ project running until 30th September 2022

\section{Additional services}

Please ensure you have read the terms and conditions of use of UCL's

e-resources $[7$

Details

Title

Author

Publisher

Creation Date

Identifier
A Mindsponge-Based Investigation into the Psycho-Religious Mechanism Behind Suicide Attacks / Quan-Hoang Vuong, Minh-Hoang Nguyen, TamTri Le.

Quan-Hoang Vuong author. >

Tam-Tri Le, author.; Minh-Hoang Nguyen, author. >

Warsaw ; Berlin : Sciendo

2021

ISBN:

9788366675599

ISBN:

9788366675582 
ruIIIId

Language

Notes

UCL local notes

Electronic reproduction. Berlin : Walter de Gruyter GmbH, (C2021. Available in PDF and EPUB formats. Description based on contents viewed 9 August 2021.

In English.

uclebkebadegruyter201803 mrcebadegruyter20210809

UCL username and password required for access.

(UCL internal use only) 9931183884404761

\section{Links}

Link to Resource

More $\left(\right.$ WorldCat $\left.^{\circledR}\right)$

Search Library Hub Dis̀cover

Search Senate House Library

Table of Contents

\section{Get It}

Your search did not match any physical resource in the library In order to receive options to request the resource from other libraries, please sign in 


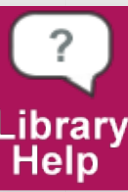


*Permalink:

https://ucl-new-

primo.hosted.exlibrisgroup.com/permalink/f/5qfvbu/UCL LMS DS51350493170004761

(Accessed: September 19, 2021) 